\title{
Case Series of Neurotrauma Managed by General Surgeon at Ladakh — The Highest Plateau State of India
}

\author{
Padma Deskit $^{1}$ (D) \\ Received: 1 February 2021 / Accepted: 12 June 2021 /Published online: 24 June 2021 \\ (c) Association of Surgeons of India 2021
}

\begin{abstract}
Trauma including neurotrauma is one of the major killers in the world. The health infrastructure in developing countries has a huge disparity, with super specialist care confined to big cities only. Adding to this problem is factors like poverty, poor road condition and no organised emergency evacuation system. The utopian scenario where specialist and infrastructure are made available in every village is a distant dream. So at present, the most feasible and cost-effective way to prevent death due to neurotrauma in rural and remote setting is putting the general surgeon working in remote area at the forefront. Our study is an effort in this direction and is reporting operative management of patients with neurotrauma in remote high-altitude Ladakh. So today, the need of hour is continuing skill enhancement training for capacity building of rural surgeon, where they are trained to do burr hole and craniotomy for reducing mortality and morbidity from neurotrauma.
\end{abstract}

Keywords Neurotrauma $\cdot$ Rural and remote places $\cdot$ General surgeon $\cdot$ Ladakh

\section{Introduction}

Traumatic brain injuries are a leading cause of morbidity, mortality, disability and socioeconomic losses in India and developing countries [1]. However, two billion people worldwide lack access to the basic surgical services and this problem is compounded in case of specialised technology necessary for neurosurgical procedure [2]. In India, it is estimated that 800 million Indian living in rural and suburban places have limited access to general neurosurgical services as the centre of excellence for neurosurgical care is concentrated around cities [3]. So in such places, the resultant death and residual disability in patients depend upon how quickly and safely they are transported. But even evacuation is not possible in some remote places like Ladakh.

Ladakh constitutes the easternmost trans-Himalayan plateau state of India, bordering Pakistan and China. Truly described as cold arid desert, the region is one of the coldest and most elevated inhabited regions of the world. It is located at altitude ranging from 2800 to $4500 \mathrm{~m}$ above sea level. The hostile terrain and climate keep its people

Padma Deskit

drpadmadeskit@gmail.com

1 SNM Hospital, Leh-Ladakh, India 194101 landlocked from the rest of the world for nearly 6 months (winters) of year because of heavy snowfall during winters which renders the high mountain passes blocked for surface transport. During this period, when evacuation failed (for various reasons), the only way out was the general surgeon operating upon the cases of neurotrauma to save lives and reduce disability. Our experience will motivate others located in similar locations to endeavour at their end with the available resources at their hand and save a life.

\section{Patients and Method}

This paper is a case series analysis of seven patients who had traumatic head injury and were operated upon in Ladakh by a general surgeon from November 2017 to November 2020. In absence of a neurosurgeon and well-equipped ICU in the entire Ladakh region, most of the patients requiring neurosurgical consultation are referred to Delhi (940 km away from Leh) or Srinagar (435 km away) via commercial flight and sometimes by road which takes a lot of precious time period of the patient, depending upon the weather condition.

On many occasions, patients could not be evacuated for various reasons like inclement weather, financial and logistic issues and poor general condition, leading to refusal by airlines to board. So these patients were operated upon at Leh 
and Nubra itself. The operations were facilitated by guidance provided by the neurosurgeons at AIIMS and a neurosurgeon at SKIMS Kashmir through telecommunications (via mobile phones). The objective of this study was to find out the feasibility and the outcome of operating on neurotrauma by general surgeon in remote places where the services of neurosurgeon are not available.

Patient's characteristics like age, sex, mechanism of injury, time of presentation to hospital after trauma, alcohol intake at the time of injury, associated injuries and comorbidities and reason for evacuation failure, type of neurosurgical procedure performed and place of surgery were evaluated. The patients were then assessed for early (within $48 \mathrm{~h}$ ) and late (beyond $48 \mathrm{~h}$ ) complications. Those cases which presented as polytrauma with other life-threatening injuries were not included. All the cases have been operated by the author at various places depending upon her place of posting. One case was operated at an army hospital when army evacuation failed.

\section{Results and Observation}

Leh district has a population of 1.33 lakhs. Annually, an average of 10 patients are referred to tertiary care centre outside Leh from the only district hospital for neurosurgical consultation outside the region. Therefore, considering the small population size of the district, the neurological case series of 7 people that too operated upon by a general surgeon thus become imperative.

\section{Clinical Profile of Patient}

The patients included in this study were in the age group of 33-77 years. All patients were male. Five out of seven patient sustained injuries due to fall, and only two patients were injured in road traffic accident. In our study, 4 out of 7 patients had extradural haematoma, 2 had chronic subdural haematoma and one patient had acute subdural haematoma. Out of the seven, three patients had haematoma confined to the frontotemporal region, two had haematoma confined to frontotemporoparietal region and 2 patient had haematoma in the temporoparietal region. Alcohol intoxication at the time of injury was seen in three out of seven patients, with one of them being a case of alcohol-induced liver disease (Table 1).

Ladakh being geographically vast area with sparse population density and high passes, absence of an emergency evacuation system adds to the woes. In our case, only 2 patients reached within $1 \mathrm{~h}$ of trauma. One of them (Patient 2) took 2 weeks, only to reach Leh. Such delay increases secondary brain damage worsening the outcome
(Table 1). Most of the patients of road traffic accident have associated injury and they present as polytrauma. Three out of seven patients (Patients 3, 6 and 7) had associated injuries. Patient 3 had left side haemopneumothorax, fracture thoracic vertebrae T5 and T7 and fracture left ankle. Patients 6 and 7 had fractured right clavicle and fractured limbs.

Only one patient (Patient 4) had significant comorbidity in the form of alcoholic liver disease and chronic active hepatitis $B$ and was in status epilepticus at presentation which could be either due to neurotrauma or due to chronic alcohol abuse. He sustained a cardiac arrest on the table while trying to achieve haemostasis on the table.

Glasgow coma score was assessed at the admission and was used to follow up with the patient over the next $6 \mathrm{~h}$. Though in our case, only three patients reported within $1 \mathrm{~h}$ of sustaining injury; in them, the GCS at arrival was 15/15 but showed a rapid deterioration in GCS score over the next few hours so the need of repeated assessment cannot be overemphasised especially if you are working in resourcelimited setting with limited staff and overburdened outpatient department. Also in resource-limited setting, it is rather advisable to shift the patient for NCCT after elapsed of few hours rather than doing it immediately on arrival keeping in view the dynamic nature of the head injury. Also in certain situation as in Patient 4, exact GCS could not be assessed as he was inebriated and was actively convulsing.

The surgeries were performed at government SNM hospital Leh and sub-district hospital Nubra under general anaesthesias. One patient was operated at an army field hospital by the author after a failed evacuation.

Duly informed detailed consent was taken from the relatives, which were duly countersigned by the medical superintendent and block medical office (Patient 5). For Patient 4 , consent was given by the medical superintendent as he was a vagabond.

The surgeries were performed using craniotomy set consisting of Hudson brace, perforator, burrs, nibblers and Gigli saw. Haemostatic agents like cellulose and gel foam were not available in hospital supply, so at some place, they were bought from the pharmacy outside the hospital in Leh while in some places, like sub-district hospital, the operating surgeon procured it from her own pocket.

Two patients underwent burr hole evacuation of clot for subdural haematoma. One of the patients underwent craniectomy with evacuation of subdural clot and duraplasty using the temporalis fascia. For the remaining four patients with extradural haematoma, one patient had cardiac arrest on table while the other two underwent craniectomy with evacuation of clot and dural hitching. One of them (Patient 7) underwent craniotomy with elevation of depressed fragment, evacuation of clot and ligation of middle meningeal artery and dural hitching (Table 1, Fig. 1). 


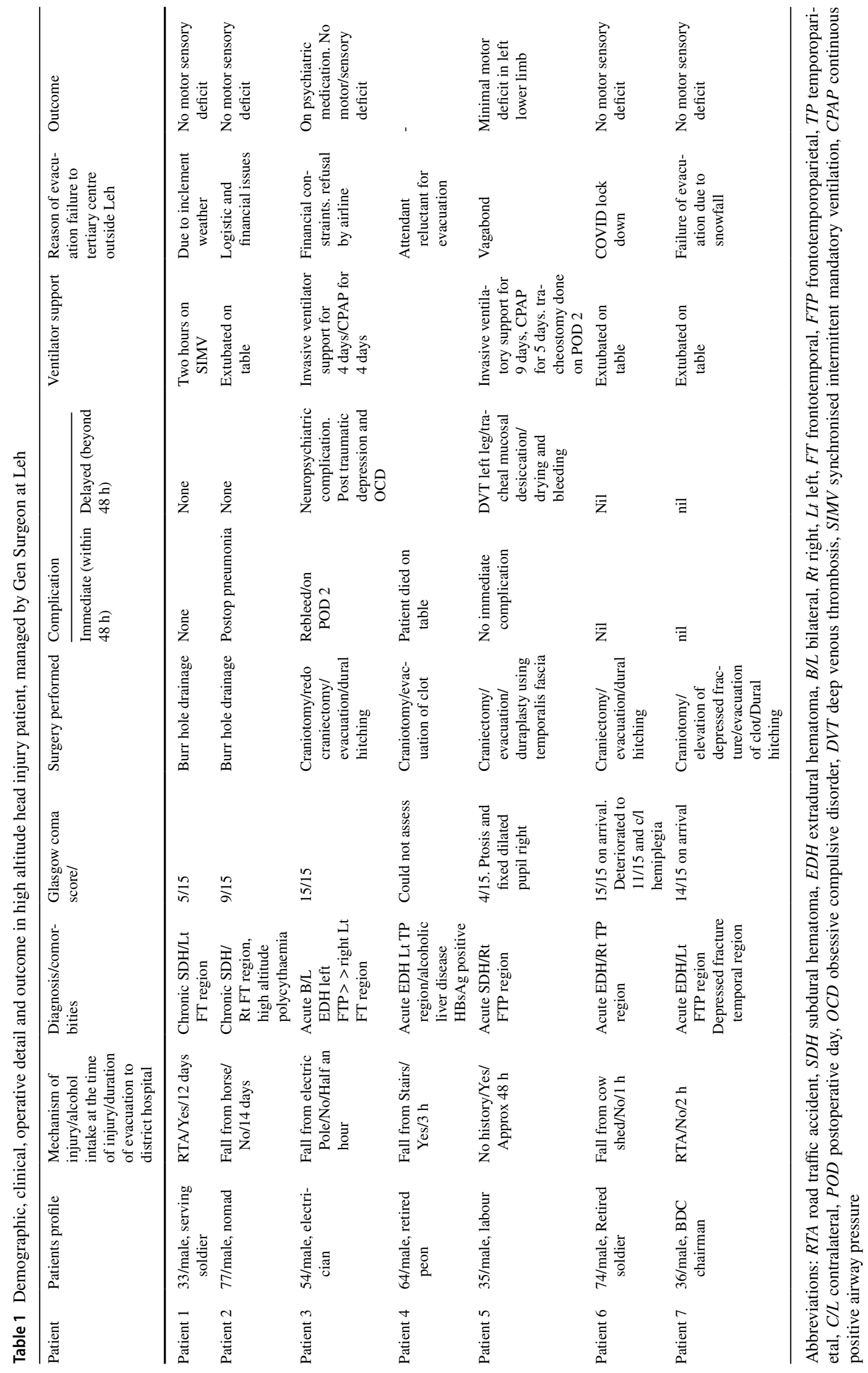




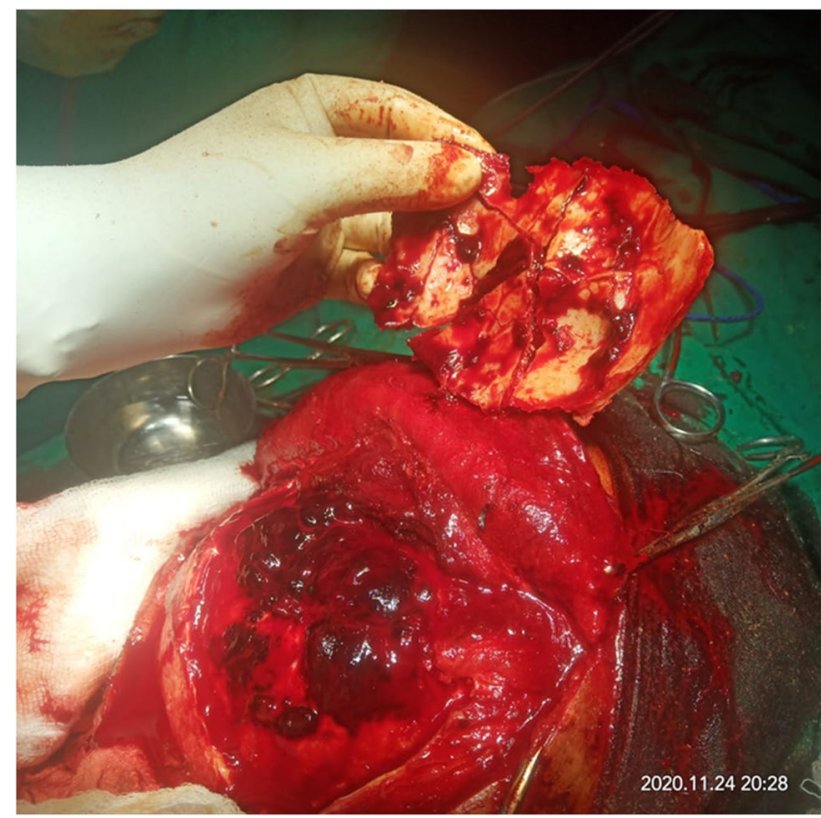

Fig. 1 Operative photograph of frontotemporal craniotomy showing a solid epidural haematoma with adjacent oozing dural surface, along with clearly visible fracture lines

In the immediate postoperative period, Patient 3 developed rebleed on the second postoperative day and had to undergo redo surgery for evacuation of bleed. We got one of the most gratifying results in Patient 5 who developed various postoperative complications. He was the first patient in the history of the whole Ladakh to be on ventilator support for 9 days due to which a tracheostomy was performed. Managing a tracheostomy in arid region for a fortnight with zero humidity and no air conditioning was a challenge in itself. Another challenge in this case was absence of attendant, but the nursing staff provided a commendable nursing care to him (Table 1).

We were able to manage most of the postoperative complication successfully as six out of the seven patients are doing well with minimal disability and are leading a meaningful life till date and are under regular follow up (Table 1).

In all cases, the NCCT images were sent over WhatsApp and discussed over mobile phone with professors of neurosurgery at AIIMS and SKIMS Srinagar, who guided and supported the author. However, internet services in Leh and especially in Nubra are erratic. So uploading NCCT images took very long and we actually were running around in hospital for a spot with better connectivity.

\section{Discussion}

India is undergoing a rapid socio-demographic and epidemiological transition. This is due to rapid urbanisation, industrialisation, motorisation and changing lifestyle.
This transition has given rise to a plethora of problems including traumatic brain injury. Traumatic brain injury is a major problem in India leading to death and disability in young and productive age group of the society. A rough estimate from India indicates that 1.6 million individuals have traumatic brain injury and seek hospital care annually $[4,5]$. As traumatic head injury mainly affects the young and the productive sections of society, it results in significant socio-economic losses as poor people living in remote and rural areas sustain higher number of traumatic brain injuries and paradoxically, they are the ones who have limited access to neurosurgical care. An estimated 800 million Indians living in rural and suburban area have limited access to neurosurgeons due to distance and poverty [6].

India has 1800 neurosurgeons for 1.27 billion people. Of the 330 approved medical colleges, only 59 have neurosurgical department recognised for MCh neurosurgery training [7]. Adding to it is the scarcity of research on traumatic brain injury from low- and middle-income countries including India. A systematic review on quantitative research on traumatic brain injury in India found that only a dismal 72 manuscripts were published over 27 years. With no study from rural and non-academic medical centre where two-thirds of Indian population live, so the available data is not a true representation. Therefore, there is a need of nurturing partnership with rural centre and urban centre with more resources [5,8]. This hand holding will give a boost to research which in turn will help to formulate a uniform guidelines and policies for management of traumatic brain injury in austere environment also.

The problem of human resource cannot be solved overnight even though the government of India is building a network of trauma centre. So an alternative way of tackling neurotrauma is building partnership between rural and tertiary centre and managing neurotrauma by general surgeon in rural and remote areas [9].

Such practice of managing neurotrauma by general surgeon in austere condition has been suggested and approved even in ATLS module Head Trauma 2008 (advance trauma life support; student manual, $10^{\text {th }} \mathrm{Ed}$, American College of Surgeon, Chicago IL: 102;126) [10]. Neurosurgeon with his vast experience of working in tropic suggested that damage control surgery for the brain could be best justified if emergency evacuation is done by the rural surgeon within the golden hours after trauma [11].

A fully credentialed general surgeon who is motivated and trained can perform up to $90 \%$ all level 1 neurosurgical procedure. Such programme has been a success in both developed and developing countries like Sweden, Australia, Nepal, Tanzania and Nigeria [12-17]. In fact, a general surgeon should have the mandate to do basic orthopaedic and ENT surgeries in remote settings. 
From Indian perspectives, very few publications are available describing the role of general surgeon in neurotrauma. But in olden days, a general surgeon would routinely perform neurosurgery. Doyens of neurosurgery in India like Dr PN Tandon, Dr V S Dave, Dr Pritam Das and Dr C.K. Gupta were general surgeons who routinely performed neurosurgery. However, in modern India, the author could not find any article from a rural surgeon in India on his/her experiences with neurotrauma. An article from the apex trauma centre AIIMS strongly recommended that the burden of neurotrauma should be equally shared between neurosurgeon and trauma surgeon [18]. Though a trauma surgeon after MCh trauma course is a step in the right direction, a doubt exists about the availability of such super specialist in resource sparse place. Instead, it has been advocated that the best and the only feasible means to overcome the gap is providing 6 month training to the motivated general surgeon from austere places at tertiary centres and training them to tackle the hidden epidemic of neurotrauma [19]. Another module in this regard came from Tanzania, a developing country like India, where 'teach forward programme' was started, rather than general surgeon going to tertiary centre, a trained neurosurgeon went and worked in the community of interest and trained local professional, who in turn trained others in the community [15].

But such practise of managing neurotrauma in peripheral setup is not without challenges. First and foremost, in our cases, even drugs needed for managing neurotrauma conservatively also like diazepam, mannitol, haloperidol and epition are always in short supply. Secondly, without an efficient evacuation system with ill equipped ambulances and untrained staff, the golden hour is lost. Even shifting the patient to district headquarters for CT scan is a task in itself. Such hindrances can be easily overcome if on the lines of neurosurgical society of Australia, the government of India also starts a national neurotrauma programme with guidelines for managing neurotrauma in peripheral institute $[12,20,21]$. Though creating a high-end ICU in austere environment is not feasible, with the COVID-19 pandemic, ventilators have reached every sub-district hospital, so it can be used in future.

Other roadblocks are the mindset of people, unrealistic societal expectation and increasing medico legal litigation and pressure from patient's attendant. Such issues can be resolved only and only if the surgeons are credentialed, trained and a policy maker bring clear cut legislation about referral and intervention.

However, one important advantage in this regard these days is telecommunication boom. With mobile connectivity reaching every village, it can be used for getting connected to the super specialist sitting anywhere in the world. Studies suggested at enabling less trained onsite medical personnel placed in distant and medically deprived area with information and guidance for neurosurgical management through telemedicine [22, 23]. Some authors stated that telemedicine in rural and suburban India has very little utility in emergency setup [24]. For using telecommunication to the fullest even in emergency set up is training and preparing the rural surgeon to tackle the emergency, providing them with protocol and referral support as described by neurosurgeon in literature [19]. Such practice is being successfully followed in developed countries like Norway [25].

\section{Conclusion}

Using search engines like pub med and Google, we could not get any relevant publication about general surgeon performing neurotrauma in India. Keeping in view the outcome from our study, and as recommended by others, we are of the opinion that neurotrauma in rural area should be taken care of by the general surgeon in consultation with the neurosurgeon in tertiary centres. Also in lines with Australia, a clear cut guideline from the ministry of health government of India needs to be put in place regarding management and transfer which would not only streamline the care but would also protect the primary care giving general surgeon from medical litigation which is a major deterrent for the surgeons. Also, the proposal of the government of India to give truncated training to motivated general surgeon in rural India in managing and operating neurotrauma should be implemented in letter and spirit to reduce the impact of hidden epidemic. With telecommunication available even in remote areas, not only the trauma but also the effective follow-up of the malignancies and other ailments operated at tertiary care centre can be provided at district level at patient doorsteps.

Supplementary Information The online version contains supplementary material available at https://doi.org/10.1007/s12262-021-03002-x.

Acknowledgements The author extends gratefulness to Dr Sachin Borkar and Dr Manmohan, from the Department of Neurosurgery, AIIMS, New Delhi, and Dr Sarabjeet SKIMS Srinagar, Dr Amitabh, neurosurgeon, VIMHANS. The author will always be in debt to Dr Sachin for instilling confidence and capacity building.

\section{Declarations}

Consent to Participate The author certifies that she has obtained all appropriate patient consent forms. The consents have given permission for their images and clinical information to be reported in the journal. The patients understand that their names and initials will not be published or revealed.

Conflict of Interest The author declares no competing interests. 


\section{References}

1. Maas AI (2017) Traumatic brain injury in India: a big problem in need of data. Neurol India 65:257-258. https://doi.org/10.4103/ 0028-3886.201848

2. Meera JG et al (2015) Global surgery 2030: evidence and solution for achieving health, welfare, and economic development. Lancet 386:569-624. https://doi.org/10.1016/S0140-6736(15)60160-X

3. Ganapathy K (2013) Neurosurgery in India: an overview. World Neurosurgery 79:621-628

4. Gurung G (2002) Epidemiology of traumatic brain injuries in Indian scenario. Neurol Research 24:24-28

5. Maas R, Andrew AI (2017) Traumatic brain injury in India; a big problem in need of data. Neurol India 65(2):257-258

6. Ganapathy K (2015) Distribution of neurologist and neurosurgeon in India and its relevance to telemedemic Medicine. Neurol India 63(2):142-154

7. Raj A, Agrawal A (2018) Neurosurgery in India: success and challenges. Int J Acad Med 4:89-90. https://doi.org/10.4103/IJAM. IJAM_67_17. Available from: https://www.ijam-web.org/text.asp? 2018/4/1/89/230851. Accessed 24 Dec 2020

8. Massenburg BB, Veetil DK, Raykar NP, Agrawal A, Roy N, Gerdin M (2017) A systematic review of quantitative research on traumatic brain injury in India. Neurol India 65:305-315

9. Upadhyayula PS, Yue JK, Yang J, Birk HS, Ciacci JD (2018) The current state of rural neurosurgical practice: an international perspective. J Neurosci Rural Pract 9(01):123-131

10. Head Trauma (2018) Advanced trauma life support-student course manual, 10th edn. American College of Surgeons, Chicago, pp $102-126$

11. Rosenfeld JV (2004) Damage control neurosurgery. Injury 35(7):655-660

12. Luck $\mathrm{T}$ et al (2015) Emergency neurosurgery in Darwin: still the generalist surgeons responsibility. ANZ J SURG 85:610-614

13. Ghimire P, Yogi N, Acharaya GB (2012) Management of head injury by general surgeons in general hospital. Nepal J Med Sci 1(1):19-22

14. Campbell N A, Kitchen G, Campbell I (2011) Operative experience of general surgeons in rural hospital. ANZ J Surg 81:601603, Pub med, Google scholar
15. Ellegala D B et al (2014) Neurosurgical capacity building in the developing world through foccused training. J Neurosurg 121: 1526-1532. Pubmed, Google scholar..

16. Fischertrom A, Nyholm L, Lewen A, Enbald P (2014) Acute neurosurgery for traumatic brain surgeons in Swedish county hospitals: a regional study. Acta Neurochir (Wien) 156(1):177-185

17. Gbalipre FB, Cliford OE (2014) Pattern, outcome and management of head injury by general surgeons at the accident and emergency department of the Niger delta university teaching hospital (NDUTH) Okolobiri, Bayelsa state of Nigeria. Palgo J Med Med Sci 1(1):1-6. Available from: https://palgojournals.org/PJMMS/ PDF/2014\%20PDF/September/Fente\%20and\%20Odjugo.pdf. Accessed 23 Dec 2020

18. Rattan A, Kumar S, Gupta A, Mishra B (2019) Management of patient with neurotrauma by trauma surgeons: need of the hour. Indian J Neurotrauma 16:82-85

19. Pandey P (2019) Should trauma Surgeon perform neurosurgery emergencies. Indian J Neurotrauma 2019(16):87

20. Byrne RW et al (2008) Neurosurgical emergency transfers to academic centres in Cook county: a prospective multicenter study. Neurosurgery 62:709-716

21. Simpson D et al (1984) Neurological injuries in South Australia: the influence of distance on management and outcome. Aust N Z J Surg 54:29-35

22. Sinha M (2016) Emergence and future of telemedicine in traumatic brain injuries in India. Indian J Neurotrauma 13:177-178

23. Sinha VD, Tiwari RN, Kataria R (2012) Telemedicine in neurosurgical emergency: Indian perspective. Asian J Neurosurg 7:75-77. Available from: https://www.asianjns.org/text.asp? 2012/7/2/75/98648

24. Ganapathy K, Ravindra A (2009) Telemedicine in India: the Apollo story. Telemed J E Health 15(6):576-585. https://doi.org/ 10.1089/tmj.2009.0066. Available at: https://pubmed.ncbi.nlm. nih.gov/19659414/. Accessed 4 Jan 2020

25. Zanaboni P, Wootton R (2016) Adoption of routine telemedicine in Norwegian hospitals: progresss over 5 years. BMC Health Serv RAES 16:496. PMC free article, Pubmed, Google scholar

Publisher's Note Springer Nature remains neutral with regard to jurisdictional claims in published maps and institutional affiliations. 